\title{
Hubungan Pencegahan HAis Perawat dengan Kejadian Flebitis di Unit Rawat Inap Bangsal Kelas III RSUD Wonosari Gunung Kidul
}

\author{
Yeni Mawang Putri ${ }^{1}$, Siti Nurunniyah', Daru Estiningsih' \\ Universitas Alma Ata, Yogyakarta, Indonesia \\ Email: yenimawangput@gmail.com
}

\begin{abstract}
Abstrak
Rumah Sakit pasti terdapat yang namanya infeksi,infeksi yang sering terjadi adalah infeksi nosokomial atau yang sekarang sering disebut HAls (Healthcare associated Infection).Salah satu infeksi nosokomial yang sering didapatkan pasien rawat inap selama dirawat adalah flebitis,dimana pasien yang mendapatkan terabi obat melalui IV Line atau selang infus. Terjadinya flebitis dapat disebabkan oleh tenaga medis yang melakukan tindakan pemasangan infus,cuci tangan,perawatan infus, penggunaan APD yang tidak sesuai SOP. Angka kejadian flebitis di RSUD Wonosari masih tinggi yaitu pada tahun 2016 terdapat 131 kejadian flebitis. Angka kejadian flebitis sering terjadi di bangsal Syaraf (Bakung) dan Bangsal Umum (Mawar dan Anggrek) dengan kejadian tertinggi yaitu pada bulan Agustus. Tujuan Penelitian ini untuk mengetahui hubungan pencegahan HAls dengan kejadian flebitis pada pasien rawat inap bangsal kelas III di RSUD Wonosari. Metode Penelitian: Penelitian ini merupakan penelitian kuantitatif dengan rancangan cross sectional. Populasi pada penelitian ini adalah seluruh pasien yang terpasang infus di bangsal rawat inap RSUD Wonosari yang berjumlah 170 orang. Pengambilan sampel pada penelitian ini menggunakan teknik accidental sampling jumlah sampel sebanyak 120 responden. Analisis data menggunakan uji statistik Kendall-Tau. Instrumen penelitian menggunakan lembar observasi. Hasil penelitian menunjukan bahwa tindakan tidak sesui dengan SOP dengan tidak terjadi flebitis sebesar 26 pasien $(21,7 \%)$, tindakan yang sesuai SOP dengan terjadi flebitis sebesar 17 pasien $(14,2 \%)$. Sedangkan tindakan yang sesuai SOP dengan tidak terjadi flebitis sebesar 75 pasien (62,5\%), dan tindakan yang sesuai SOP dengan terjadi flebitis sebesar 2 pasien $(1,7 \%)$. Berdasarkan hasil analisis Kendal Tau diperoleh nilai $p$ value $0,000(p<0,05)$ yang artinya ada hubungan pencegahan HAis (Hospital Associated Infection) perawat dengan kejadian flebitis di unit rawat inap bangsal kelas III. Ada hubungan antara pencegahan HAls dengan kejadian flebitis di unit rawat inap bangsal KELAS III RSUD Wonosari Gunung Kidul 2017.
\end{abstract}

Kata Kunci: Pencegahan HAls, Flebitis

The Relationship Between The Prevention of HAis Nurse With Phlebitis Events In Inpatient Unit in Class III Ward Regional Public Hospital in Wonosari Gunung Kidul

\begin{abstract}
In the hospital, the most common infection is a nosocomial infection or what is now commonly called HAls (Healthcare associated Infection). One of the most common nosocomial infections that the inpatients often get during hospitalization is phlebitis, in which patients get medicine therapy through IV Line or infusion hose. The occurrence of phlebitis can be caused by medical personnel who perform the action of infusion, hand washing, infusion treatment, use of PPE that does not comply with SOP. The incidence of phlebitis in RSUD Wonosari is still high that in 2016 there were 131 phlebitis incidence. The incidence of phlebitis often occurs in the Nerve Ward (Bakung) and the General Ward (Mawar dan Anggrek) with the highest incidence is in August. The objective to know the relationship of HAls prevention with phlebitis occurrence in inpatient class III ward in regional public hospital of Wonosari. This research is a quantitative research with cross sectional design. The population in this research were all patients who were infused in inpatient ward of Wonosari regional public hospital which
\end{abstract}


amounted to 170 people. The sampling in this research is using accidental sampling technique with the number of samples of 120 respondents. Data analysis used Kendall-Tau statistic test. The research instrument uses an observation sheet. The results showed that the action was not in accordance with the SOP with no phlebitis occurred for 26 patients (21.7\%), the appropriate action of SOP with the occurrence of phlebitis of 17 patients (14.2\%). While the appropriate action of SOP with no occurrence of phlebitis amounted to 75 patients $(62.5 \%)$, and the appropriate action of SOP with the occurrence of phlebitis of 2 patients (1.7\%). Based on the Kendal Tau analysis results, it is obtained $p$ value $0,000(p<0.05)$ which means there is a relationship of hais prevention (Hospital Associated Infection) nurse with the incidence of phlebitis in ward class III inpatient unit. There is a relationship between the prevention of HAls and the incidence of phlebitis in ward CLASS III inpatient unit in regional public hospital of Wonosari Gunung Kidul 2017.

\section{Keywords: Prevention of HAls, phlebitis}

Received: 02/03/2019; published: 01/05/2019

\section{PENDAHULUAN}

HAl's (Hospital Associated Infection) merupakan infeksi yang terjadi pada pasien rawat inap setelah 3×24 jam berada di rumah sakit yang di tandai dengan adanya manifestasi klinis dari infeksi. HAl's terdiri atas beberapa macam infeksi antara lain adalah Infeksi Saluran Kemih (ISK), dekubitus, Infeksi Luka Operasi (ILO), flebitis dan lain-lain (1). The Cententers of Disease Control dan Prevention (DCD) mendefinisikan Hospital Associated Infection sebagai infeksi yang didapatkan penderita selama pengobatan untuk kondisi lain atau petugas kesehatan mendapatkan infeksi saat bertugas di pelayanan kesehatan (2). Infeksi nosokomial merupakan infeksi serius dan berdampak merugikan pasien karena harus menjalani perawatan di rumah sakit lebih lama. Standar kejadian HAls (Healthcare Associated Infection) di rumah sakit sebesar $\leq 1,5 \%$.

Saat ini angka kejadian infeksi nosokomial menjadi salah satu pedoman mutu pelayanan rumah sakit. Izin operasional sebuah rumah sakit bisa dicabut karena tingginya angka kejadian HAls (Healthcare Associated Infection.) Penyakit infeksi menjadi salah satu penyebab tingginya angka kesakitan dan kematian di dunia. Salah satu jenis infeksi adalah HAls (Healthcare Associated Infection). Infeksi ini menyebabkan 1,4 juta kematian setiap hari di seluruh dunia. Penyakit infeksi ini menempati posisi pembunuh keempat di Amerika Serikat setiap tahun terdapat 20.000

kematian akibat infeksi nosokomial. Kejadian infeksi nosokomial di Malaysia sebesar 12,7\%. HAls (Healthcare Associated Infection) masih menjadi masalah utama dunia. Penerapan kewaspadaan umum merupakan bagian pengendalian infeksi yang tidak terlepas dari peran masing- masing pihak yang terlibat didalamnya yaitu pimpinan, staf administrasi, pemberi pelayanan maupun pengguna jasa termasuk pasien dan pengunjung. Hal ini tentunya pemberi pelayanan kesehatan terutama perawat sangat berperan penting terhadap 
pencegahan infeksi nosokomial karena perawat merupakan salah satu anggota tim kesehatan yang berhubungan langsung dengan pasien dan bahan infeksius di ruang rawat dalam menilai kinerja perawat salah satunya adalah dengan melakukan penilaian terhadap kegiatan perawat dalam memberikan asuhan keperawatan sesuai dengan standar operasional prosedur dan standar asuhan keperawatan (4).

Kinerja individu dapat dipengaruhi oleh beberapa faktor antara lain faktor individu (pengetahuan, kemampuan, keterampilan, latar belakang, dll), faktor psikologis (persepsi, sikap, motivasi dan kepribadian), dan faktor organisasi (sumber daya, kepemimpinan dan supervisi). Motivasi atau dorongan dalam melakukan suatu pekerjaan memiliki kontribusi terhadap kinerja perawat. Dukungan dan supervisi kepala ruangan terhadap kinerja perawat pelaksana sangat dibutuhkan dalam upaya pencegahan infeksi nosokomial. Supervisi dilakukan untuk mengetahui sejauh mana kemampuan perawat pelaksana dalam melakukan tindakan pencegahan infeksi nosokomial (3).

Faktor penentu bagi mutu pelayanan dan citra masyarakat di mata masyarakat. Melihat keadaan yang ada ternyata kegiatan pelayanan keperawatan di Rumah Sakit sesungguhnya terpusat pada Ruang Rawat Inap, dimana perawatan pasien dilakukan selama 24 jam secara terus menerus dengan penerapan suatu konsep pelayanan profesional yaitu proses asuhan keperawatan oleh pelaksana keperawatan. Salah satu pelayanan kesehatan dalam bidang asuhan keperawatan adalah pemberian terapi pengobatan di Rumah Sakit biasanya berupa terapi intravena ataupun terapi peroral, dimana pemberian terapi intravena diberikan obat lewat pemasangan infus. Untuk itu pemberian terapi intravena saat ini merupakan yang paling banyak digunakan untuk mengatasi berbagai kondisi pasien (1).

Salah satu strategi yang sudah terbukti bermanfaat dalam pengendalian infeksi nosocomial adalah peningkatan kemampuan tugas kesehatan dalam metode universal precautions. Universal precautions yaitu suatu cara penanganan baru untuk pencegahan infeksi yang mengurangi resiko penularan dari patogen yang ditularkan melalui darah atau cairan tubuh diantara pasien dan pekerja kesehatan (7). Apabila terapi intravena diberikan dalam jangka panjang dapat menimbulkan beberapa komplikasi, diantaranya adalah flebitis.

Flebitis adalah infeksi yang berkaitan dengan pemakaian kateter intra vena. Flebitis adalah salah satu bentuk HAls yang sering muncul dirumah sakit, yaitu merupakan peradangan pada dinding vena akibat terapi cairan intravena, yang ditandai dengan nyeri, kemerahan, teraba lunak, pembengkakan dan hangat pada lokasi penusukan jarum infus (4). Flebitis didefinisikan sebagai peradangan pada dinding pembuluh darah balikatau vena (5). Flebitis adalah peradangan pada tunika intima vena yang terjadi karena komplikasi pemberian terapi intra vena (IV) yang di tandai dengan bengkak, kemerahan sepanjang vena, nyeri, peningkatan suhu pada daerah insersi kanula dan penurunan kecepetan tetesan infus (6). 
Faktor-faktor yang ikut berperan dalam flebitis bakteri, meliputi teknik aseptik termasuk didalamnya kebersihan tangan petugas, lama perawatan, alat atau cairan yang terkontaminasi (7).

Di Indonesia belum ada angka yang pasti tentang prevalensi kejadian flebitis, hal ini disebabkan oleh penelitian dan publikasi yang berkaitan dengan flebitis jarang dilakukan. Dari data Depkes RI Tahun 2013, angka kejadian flebitis di Indonesia sebesar 50,11\% untuk Rumah Sakit Pemerintah sedangkan untuk Rumah Sakit Swasta sebesar 32,70\% .Pada evaluasi dan penatalaksanaan pasien infeksi yang didapat di Rumah Sakit, diperkirakan bahwa 3-5\% yang di rawat di Rumah Sakit Amerika Serikat mendapatkan infeksi baru, yang menyebabkan sekitar 2 juta infeksi nosokominal per tahun dan biaya per tahun melebihi 2 milyar dolar. Flebitis adalah inflamasi lapisan vena yang disebabkan oleh faktor mekanik, kimia, maupun teknik aseptik yang kurang baik. Karateristik flebitis adalah adanya kemerahan pada area tusukan nyeri, bengkak, pengerasan sepanjang vena, dan panas.

Di RSUD Kota Semarang masih terdapat kasus pada tahun 2012 dengan jumlah kejadian 53 dari 47641 jumlah pasien terpasang infus. Dan meningkat menjadi 55 kejadian per 6 bulan selama tahun 2013 dengan jumlah kejadian 47641 pasien terpasang infus. Pelaksanaan peran perawat dalam pengendalian infeksi nosokomial di RSUD Kota Semarang, saat ini masih dijumpai perawat yang tidak mematuhi prosedur pencegahan infeksi noskomial yang telah dibuat oleh rumah sakit. Perilaku dan sikap perawat terhadap infeksi nosokomial berperan penting dalam pencegahan infeksi nosokomial di RSUD Kota Semarang. Sikap yang baik maupun buruk, tergantung dari keyakinan penerapan pengetahuan, keyakinan, budaya kerja, dan sikap perawat dalam menjalankan tindakan medis sesuai SOP yang berlaku. Berdasrkan study pendahuluan hasil wawancara dengan ketua tim PPI pada tanggal 20 Februari 2017 didapatkan data primer dalam 1 tahun terakhir terdapat kejadian flebitis sebanyak 131 kejadian flebitisdi RSUD Wonosari Gunung Kidul. Didukung hasil penelitian Imram Radne dan Eva $(8,14)$.

\section{BAHAN DAN METODE}

Penelitian ini dilaksanakan di unit rawat inap bangsal kelas III RSUD Wonosari Gunung Kidul, pada tanggal 20 Maret sampai dengan 20 April 2017. Menggunakan metode penelitian Kuantitatif (non eksperimen) dengan metode pengambilan sampel menggunakan teknik Accidental. Dengan pendekatan CrossSactional. Jumlah sampel yang memenuhi kriteria sebanyak 120 responden. Variabel bebas adalah pencegahan hais (hospital associated infaction) perawat dan variabel terikat adalah kejadian flebitis. Analisis univariat menggunakan tabel distribusi frekuensi, analisis bivariat dengan Kendal Tau. Instrumen 
yang digunakan dalam penelitian ini adalah lembar observasi SOP dan VIP Score hasil adopsi dari Dougherty, L.., dkk 2010.

\section{HASIL DAN PEMBAHASAN}

Hasil Karakteristik penelitian berdasarkan jenis kelamin, usia di Unit Rawat Inap Bangsal Kelas III RSUD Wonosari tertuang pada Tabel 1 berikut:

Tabel 1 Distribusi Frekuensi Karakteristik Remaja berdasarkan jenis kelamin, usia di Unit Rawat Inap Bangsal Kelas III RSUD Wonosari

\begin{tabular}{lcc}
\hline $\begin{array}{c}\text { Karakteristik } \\
\text { Responden }\end{array}$ & $\begin{array}{c}\text { Frekuensi } \\
(\mathbf{n})\end{array}$ & $\begin{array}{c}\text { Presentase } \\
(\%)\end{array}$ \\
\hline Jenis kelamin & & \\
Laki-laki & 73 & 60,8 \\
Perempuan & 47 & 39,2 \\
Usia & & \\
Dewasa awal & 5 & 4,2 \\
Dewasa akhir & 28 & 23,3 \\
Lansia awal & 42 & 35,0 \\
Lansia akhir & 45 & 37,5 \\
*Sumber: Data Primer 2017 & &
\end{tabular}

Berdasar Tabel 1 diketahui karakteristik responden berjenis kelamin laki-laki, yaitu sebanyak 73 responden (60,8\%), dan perempuan sebanyak 47 responden $(39,2 \%)$. Hasil penelitian menunjukan bahwa usia dewasa awal sebesar 5 respoden $(4,2 \%)$, usia dewasa akhir sebesar 28 responden (23,3\%), sedangkan usia lansia awal sebesar 42 responden $(35,0 \%)$, dan usia lansia akhir sebesar 45 responden $(37,5 \%)$.

\section{Standar Operasional Prodesur (SOP)}

Tabel 2 Kesesuaian tindakan sesuai SOP pada pada pasien rawat inap bangsal kelas III RSUD Wonosari

\begin{tabular}{lcc}
\hline Kesesuaian tindakan & $\begin{array}{c}\text { Frekuensi } \\
(\mathbf{n})\end{array}$ & $\begin{array}{c}\text { Presentase } \\
(\%)\end{array}$ \\
\hline Sesuai SOP & 77 & 64,2 \\
Tidak sesuai SOP & 43 & 35,8 \\
\hline Total & 120 & 100 \\
${ }^{*}$ Sumber: Data Primer 2017 & &
\end{tabular}

Berdasarkan tabel 4.3 didapatkan hasil tindakan perawat yang sesuai SOP sebanyak 77 pasien $(64,2 \%)$ dan yang tidak sesuai SOP sebanyak 43 pasien $(35,8 \%)$.

\section{Kejadian Flebitis}

Distribusi frekuensi berdasarkan kejadian Flebitis di Unit Rawat Inap Bangsal Kelas III RSUD Wonosari tertuang dalam Tabel 3 berikut:

Tabel 3 Distribusi Frekuensi Kejadian Flebitis di Unit Rawat Inap Bangsal Kelas III RSUD Wonosari 


\begin{tabular}{lcc}
\hline Kejadian Flebitis & $\begin{array}{c}\text { Frekuensi } \\
\text { (n) }\end{array}$ & $\begin{array}{c}\text { Presentase } \\
(\%)\end{array}$ \\
\hline Tidak Flebitis & 101 & 84,2 \\
Flebitis & 19 & 15,8 \\
\hline Total & 120 & 100 \\
\hline *umber: Data Primer 2017 & &
\end{tabular}

Berdasarkan Tabel 3 didapatkan hasil bahwa pasien yang tidak mengalami flebitis 101 pasien $(84,2 \%)$ dan yang mengalami flebitis yaitu 19 pasien $(15,8 \%)$.

\section{Analisa Bivariat}

Analisis bivariat adalah analisis yang menggunakan dua variabel yaitu variabel bebas dan terikat. Teknik analisis bivariat digunakan untuk mengetahui hubungan antara Pencegahan Hais Perawat dengan Kejadian Flebitis di Unit Rawat Inap Bangsal Kelas II RSUD Wonosari, dengan uji statistik yang digunakan yaitu Kendal Tau dan dengan tingkat kemaknaan (alpha=0,05). Hasil analisis yang merupakan hubungan antara variabel bebas dan variabel terikat seperti pada Tabel 4 berikut:

Tabel 4 Tabulasi Silang antara Pencegahan Hais Perawat dengan Kejadian Flebitis di Unit Rawat Inap Bangsal Kelas III RSUD Wonosari

\begin{tabular}{ccccccc}
\hline \multirow{2}{*}{$\begin{array}{c}\text { Standar Operasional } \\
\text { Prosedur (SOP) }\end{array}$} & \multicolumn{5}{c}{ Tidak Flebitis } & \multicolumn{2}{c}{ Flebitis } & p-value & \multirow{2}{*}{$\begin{array}{c}\text { Koefisien } \\
\text { Korelasi }\end{array}$} \\
& $\mathbf{f}$ & $\%$ & $\mathbf{f}$ & $\%$ & & \\
\hline Tidak Sesuai SOP & 26 & 21,7 & 17 & 14,2 & \multirow{2}{*}{0,000} & \multirow{2}{*}{0,485} \\
Sesuai SOP & 75 & 62,5 & 2 & 1,7 & & \\
\hline Total & 101 & 35,8 & 19 & 15,8 & & \\
\hline
\end{tabular}

*Sumber: Data Promer 2017

Berdasarkan Tabel 4 diketahui hasil tabulasi silang menunjukan bahwa jika dilakukan tindakan tidak sesuai SOP maka tidak ada pasien yang mengalami flebitis sebesar 26 pasien $(21,7 \%)$, tindakan tidak sesuai SOP yang mengalami flebitis sebesar 75 pasien $(62,5 \%)$ sedangkan tindakan yang sesuai SOP maka tidak ada pasien yang mengalami flebitis sebesar 17 pasien (14,2\%), tindakan yang sesuai SOP maka pasien yang mengalami flebitis sebesar 2 pasien $(1,7 \%)$.

Hasil penelitian ini didapatkan nilai $p$ value 0,000 lebih kecil dari nilai $p$ value 0,05 $(0,000<0,05)$. Maka hipotesis dalam penelitian ini diterima yang berarti ada hubungan antara pencegahan HAls perawat dengan kejadian flebitis di unit rawat inap bangsal kelas III RSUD Wonosari Gunung Kidul. Sedangkan keeratan hubungan didapatkan hasil dengan nilai koefisien korelasi sebesar -0,485 yang berarti sedang, jika nilai dependen lebih tinggi maka nilai independen rendah. Hubungan penceghana HAls perawat dengan kejadian flebitis di unit rawat inap bangsal kelas III RSUD Wonosari Gunung Kidul. 
Berdasarkan hasil penelitian Tabel 1 menunjukkan bahwa karakteristik responden di unit rawat inap bangsal kelas III RSUD Wonosari, mayoritas berjenis kelamin laki-laki sebanyak 73 passien, dan jenis kelamin perempuan sebanyak 47 pasien. Dikarenakan lakilaki kurang memperhatikan kesehatan dirinya salah satunya yaitu kurangnya kebersihan diri dan pola hidup yang kurang baik. Sehingga mudah terjangkit penyakit seperti flebitis. Berdasarkan penelitian yang dilakukan responden yang banyak mengalami flebitis adalah berjenis kelamin laki-laki. Hal ini didukung oleh penelitian yang dilakukan Asrin, yang berjudul "Analisis Faktor-Faktor yang Berpengaruh Terhadap Kejadian Flebitis Di RSUD Purbalingga" didapatkan hasil responden laki-laki lebih sebanyak $61 \%$ dan responden wanita sebanyak $39 \%(8)$.

Sedangkan karakteristik responden berdasarkan usia dewasa awal sebanyak 5 pasien, usia dewasa akhir sebanyak 28 pasien, serta usia lansia awal sebanyak 42 pasien, usia lansia akhir sebanyak 45 pasien. Menurut Depkes RI bahwa dikatakan dewasa awal yaitu usia 26-35 tahun, dewasa akhir yaitu usia 36-45 tahun, lansia awal yaitu usia 46-55 tahun, lansia akhir yaitu usia 56-65 tahun (9). Berdasarka penelitian yang telah dilakukan diketahui bahwa hasil usia responden terbanyak adalah usia lansia akhir yaitu 45 pasien dan yang paling sedikit didapatkan pada usia dewasa awal sebanyak 5 pasien.

Hal ini dikarenakan pada usia lansia lebih banhyak mengalami sakit, dimana lansia telah mengalami proses penuaan dan fungsi organ mengalami penurunan sehingga mudah mengalami sakit. Sedangkan masa dewasa awal fungsi organ masih baik sehingga tidak banyak mengalami sakit. Penelitian ini didukung oleh penelitian yang dilakukan Rizky W, yang berjudul "Analisis Faktor yang Berhubungan dengan Kejadian Flebitis pada Pasien yang Terpasang Kateter Intravena di Ruang Bedah Rumah Sakit Ar. Bunda Prabumulih" menunjukkan bahwa usia memiliki pengaruh yang bermakna terhadap terjadinya flebitis dengan hasil responden yang sering mebgalami flebitis berada pada usia dewasa sebanyak $46 \%$, usia lansia sebanyak $46 \%$ (10).

Berdasarkan hasil penelitian pada Tabel 2 standar operasional prosedur (SOP) dapat diketahui bahwa reponden dalam melakukan tindakan sesuai SOP sebanyak 77 responden, sedangkan dalam melakukan tindakan yang tidak sesuai SOP sebanyak 43 responden. Dimana dalam setiap melakukan tidankan sesuai SOP dapat menurunkan terjadinya flebitis. Sesuai dengan penelitian yang dilakukan Suciwati, didapatkan hasil penelitian menunjukan bahwa responden yang patuh dalam menjalankan SOP pemasangan infus di SMC RS Telogorejo sebanyak 52 responden, sebanyak 47 (90,4\%) tidak terjadi flebitis dan yang terjadi flebitis $5(9,6)$ pasien $(11)$.

Pada responden yang tidak patuh dalam menjalankan SOP pemasangan infus sebanyak 22 responden. Didukung oleh penelitian Ince M, tentang kepatuhan perawat dalam 
melaksanakan standar operasional pemasangan infus terhadap flebitis di RS Batis Kediri menunjukan sebagai besar perawat memiliki tingkat kepatuhan pelaksanaan sesuai SOP, yakni sebesar $60(88,2 \%)$ sedangkan perawat yang memiliki tingkat kepatuhan pelaksanaan yang tidak sesuai SOP sebesar $8(11,8 \%)(12)$.

Berdasarkan hasil penelitian pada tabel 4.3 kejadian flebitis di unit rawat inap bangsal kelas III RSUD Wonosari, dapat diketahui bahwa responden yang tidak mengalami flebitis sebanyak 101 pasien, sedangkan responden yang mengalami flebitis sebanyak 19 pasien. Hal ini dikarenakan setiap tindakan yang dilakukan sudah sesuai dengan SOP dimana dapat menyebabkan sedikit yang mengalami kejadian flebitis pada pasien. Ketika SOP dilakukan dengan baik akan menurunkan kejadian flebitis di unit rawat inap bangsal kelas III RSUD Wonosari.

Sesuai dengan penelitian yang dilakukan oleh Triwidyanti D, hasil penelitian menunjukan bahwa yang patuh dalam menjalan SOP pemasangan infus di RSUD Tugurejo Semarang sebanyak 47 responden $(90,4 \%)$ tidak terjadi kejadian flebitis dan yang terjadi kejadian flebitis sebanyak 5 responden $(9,6 \%)$ pasien (16). Hal ini terjadi karena yang berkontribusi dengan kejadian flebitis salah satunya adalah teknik antiseptic (cuci tangan dan memakai sarung tangan) dan ini telah diatur dalam SOP pemasangan infus. Dengan perawat patuh pada SOP pemasangan infus (melakukan teknik aseptik) maka transmisi mikroorganisme pada daerah penusukan infus tidak terjadi sehingga tidak terjadi flebitis pada pasien yang dilakukan pemasangan infus oleh perawat (12).

Hasil penelitian yang dilakukan diketahui bahwa banyak yang melakukan tindakan terhadap pasien di rumah sakit sesuai dengan standar oprasional prosedur (SOP) sebanyak 77 responden. Hal ini dapat menurunkan angka terjadinya flebitis, dimana dalam melakukan tindakan yang susai SOP dapat menurunkan terjadinya flebitis terhadap pasien. Sesuai dengan penelitian yang dilakukan oleh Ince $\mathrm{M}$, didapatkan hasil bahwa dengan kepatuhan perawat dalam melakukan SOP seperti pemasangan infus tidak terjadi flebitis. Dengan perawat patuh pada SOP pemasangan infus (melakukan teknik aseptik) maka transmisi mikroorganisme pada daerah penusukan infus tidak terjadi sehingga tidak terjadinya flebitis pada pasien yang dilakukan pemasangan infus oleh perawat (12).

Sejalan dengan penelitian Suciwati, didapatkan hasil penelitian menunjukan bahwa responden yang patuh dalam menjalankan SOP pemasangan infus di SMC RS Telogorejo sebanyak 52 responden, sebanyak $47(90,4 \%)$ tidak terjadi flebitis dan yang terjadi flebitis 5 $(9,6)$ pasien. Pada responden yang tidak patuh dalam menjalankan SOP pemasangan infus sebanyak 22 responden (11). 
Hubungan Pencegahan Hais Perawat dengan Kejadian Flebitis di Unit Rawat Inap Bangsal Kelas III RSUD Wonosari Gunung Kidul. Berdasarkan hasil penelitian pada tabel 4.4 diketahui bahwa uji statistik yang dilakukan dengan menggunakan uji Kendal tau dengan bantuan program komputer SPSS didapatkan hasil nilai $p$-value sebesar $(0,000)$. Uji statistik apakah ada hubungan antara variabel bebas (independen) dengan variabel terikat (dependen) menggunakan nilai $\mathrm{p}$-value $<0,05$ yang berarti ada hubungan antara variabel bebas (independen) dengan variabel terikat (dependen).

Hasil penelitian ini diketahui nilai $\mathrm{p}(0,000)<0,05$ maka Ho ditolak Ha diterima yang artinya ada hubungan antara pencegahan hais perawat dengan kejadian flebitis di unit rawat inap bangsal kelas III RSUD Wonosari Gunung Kidul. Sejalan dengan penelitian yang dilakukan oleh Imram R.R.P dari hasil penelitian berdasarkan hasil analisis data dengan menggunkan uji Chisquare didapatkan nilai $p$-value sebesar 0,000 yang berarti nilai signifikan antara Pengaruh Infus dengan Kejadian Flebitis pada Pasien Rawat Inap di Bangsal Penyakit Dalam dan Syaraf Rumah Sakit Nur Hidayah Bantul (26).

Hasil penelitian yang dilakukan diketahui bahwa 26 responden yang tidak sesuai SOP dengan pasien yang tidak mengalami flebitis, 75 responden yang tidak sesuai SOP dengan kejadia flebitis. Sedangkan 17 responden sesuai SOP dengan kejadian tidak flebitis, 2 respponden sesuai SOP dengan kejadian flebitis. Dikarenakan dalam pemberian asuhan keperawatan seperti pemasangan infus, kateter, lamanya pemasangan kateter, yang tidak sesuai dengan SOP dapat menyebabkan terjadinya infeksi ataupun terjadinya kejadian flebitis.

Hal ini didukung oleh penelitian yang dilakukan Yulia $R$, kejadian flebitis di Ruang Rawat Inap RSUD Dr. Achmad Muchtar Bukittinggi. Penelitian dilakukan pada 106 responden yang mendapat ciran intravena. Penggantian balutan yang tidak dilakukan sebanyak 57 orang dan yang dilakukan penggantian balutan sebanyak 29 orang. Dari 57 orang yang tidak dilakukan penggantian balutan sebanyak $66,7 \%$ mengalami flebitis, dan yang tidak terjadi flebitis sebanyak $33 \%$ (14). Sesuai dengan penelitian yang dilakukan oleh didapatkan hasil bahwa dari 26 responden yang terpasang infus di vena mencapai sebanyak 76,9\% mengalami kejadian flebitis dibandingkan dengan yang tidak mengalami flebitis sebanyak 23,1\% (15).

\section{SIMPULAN DAN SARAN}

Karakteristik responden berdasarkan jenis kelamin, usia didapatkan hasil laki-laki sebanyak 73 (60,8\%), responden perempuan sebanyak 47 (39,2\%). Sedangkan karakteristik responden berdasarkan usia dewasa awal sebanyak 5 (4,2\%), usia dewas akhir sebanyak $28(23,3 \%)$, dan usia lansia awal sebanyak $42(35,0 \%)$, usia lansia akhir sebanyak 45 
(37,5\%). Standar operasional prosedur di unit rawat inap bangsal kelas III RSUD Wonosari yang sesuai SOP sebanyak 77 (64,2\%), sedangkan tindakan yang dilakukan tidak sesuai SOP sebanyak $43(35,8 \%)$ Kejadian flebitis di unit rawat inap bangsal kelas III RSUD Wonosari yang tidak flebitis sebesar 101 pasien $(84,2 \%)$, dan yang mengalami flebitis sebesar 19 pasien (15,8\%). Ada hubungan yang bermakna antara pencegahan hais perawat dengan kejadian flebitis di unit bangsal rawat inap bangsal kelas III.

\section{DAFTAR PUSTAKA}

1. Marwoto, Agus . Analisis kinerja perawat dalam pengendalian infeksi nosokomial di ruang IRNA 1 RSUP dr.Sardjito, Yogyakarta. Irc- kmpk.ugm.ac.id . 2007.

2. Notoatmodjo, S. Promosi Kesehatan dan IImu Perilaku. Jakarta : Rineka Cipta . 2007.

3. Setiawati . Analisis faktor-faktor yang mempengaruhi ketaatan petugas kesehatan melakukan hand hygiene dalam mencegah infeksi nosokomial di Ruang Perinatologi RSUPN Dr. Cipto Mangunkusumo. Jakarta. [Tesis]. Depok : Universitas Indonesia . 2009.

4. Darmadi . Infeksi Nosokomial, Problematika dan Pengendaliannya. Jakarta:Salemba Medika . (2008).

5. CDC. Identifying Healtcare- Associated Infection (HAl's) for NHSN surveillance , 2016.

6. Menteri Kesehatan Republik Indonesia Nomor 129/Menkes/SK/II/2008. Standar Pelayanan Minimal Rumah Sakit. Menteri Kesehatan RI; 2008.

7. Depkes RI . Pedoman Pelaksanaan kwaspadaan Universal dipelayanan kesehatan , Jakarta. Direktorat Jendral Pemberantasan Penyakit Menular dan Penyehatan Lingkungan . 2003.

8. Asrin. Analisis Faktor-Faktor yang Berpengaruh terhadap Kejadian Flebitis di RSUD Purbalingga . Jurnal Keperawatan Sudirman. Vol 1. No . 2006.

9. Putri IR. Pengaruh Lama Pemasangan Infus dengan Kejadian Flebitis pada Pasien Rawat Inap di Bangsal Penyakit Dalam dan Syaraf Rumah Sakit Nur Hidayah Bantul. Jurnal Ners dan Kebidanan Indonesia. 2016 Jul 1;4(2):90-4.

10. Departemen Kesehatan RI 2009. Kategori umur. Diperoleh tanggal 5 Mei 2017 dari https://yhantiaritra.wordpress.com/20 15/06/03/kategori -umur- menurut - depkes/.

11. Rizky W. Analisis Faktor yang Berhubungan dengan Kejadian Flebitis Pada Pasien yang Terpasang Kateter Intravena di Ruang Bedah Rumah Sakit Ar. Bunda Prabumumil. Jurnal Ners dan Kebidanan Indonesia. 2016;2(4): 102-108

12. Suciwati. Hubungan Kepatuhan Perawat Dalam Menjalankan SOP Pemasangan Infus dengan Kejadian Flebitis di SMC RS. Telogorejo. Jurnal IImu Keperawatan dan Kebidanan Vol 1. No 2. 2016 
13. Maria I. Kepatuha Perawat dalam Melaksanakan Standar Prosedur Oprasional Pemasangan Infus Terhadap Flebiti. 2012. www.stikesbabtisjurnal@ymail.com. Diakses tanggal 9 juni 2017

14. Nurinda E. Obat Infusi Mempengaruhi Kejadian Flebitis Pada Pasien Rawat Inap Di Bangsal Umum Rsud Wonosari Tahun 2017. INPHARNMED Journal (Indonesian Pharmacy and Natural Medicine Journal). 2018 Mar 19;1(1).

15. Yulia R. Faktor-Faktor hang Berhubungan dengan Kejadian Flebitis pada Pemasangan Infus Di Ruang Rawat Inap Bedah RSUD Dr. Achma Muchtar Bukittinggi. 2011. STIKES Perintis.

16. Kasrin R, Putra Y. Faktor-Faktor Yang Mempengaruhi Kejadian Flebitis Di Ruang Rawat Inap Interne RSUD Prof. Dr. Ma. Hanafiah SM. Batusangkar. Jurnal Kesehatan Stikes Prima Nusantara Bukittinggi. 2013. Vol 4. No 1.

17. Nurunniyah, Siti. Evaluasi Pelayanan Kesehatan Reproduksi bagi Pengungsi Rawan Bencana Erupsi Merapi. Jurnal Ners dan Kebidanan Indonesia Vol 2. No 2. Tahun 2016. https://ejournal.almaata.ac.id/index.php/JNKI/article/view/26/25.

18. Triwidyanti D. Hubungan Kepatuhan Perawat Dalam Menjalankan SOP. 